\title{
Correlação entre o California Mastitis Test (CMT) e a Contagem de Células Somáticas (CCS) do Leite de Búfalas Murrah
}

\author{
André Mendes Jorge ${ }^{1}$, Cristiana Andrighetto ${ }^{2}$, Mara Regina Barzon Strazza ${ }^{3}$, Rita de Cássia Correa ${ }^{3}$, \\ Débora Galhardo Kasburgo ${ }^{3}$, Adriana Piccinin ${ }^{4}$, Cassiano Victória ${ }^{5}$, Paulo Francisco Domingues ${ }^{6}$
}

RESUMO - O objetivo neste trabalho foi estimar as correlações entre o California Mastitis Test (CMT), a contagem células somáticas (CCS) e a produção de leite. Foram colhidas 544 amostras de leite de 38 búfalas em lactação nos anos de 2002 e 2003 . O manejo de ordenha consistiu em uma ordenha diária, em que os tetos das búfalas eram desinfectados com solução de iodo, secos individualmente com papel toalha e submetidas à ordenha mecânica. O CMT foi realizado imediatamente após higienização dos tetos e as amostras de leite foram enviadas ao laboratório do DHVSP da Unesp/Botucatu, para realização da Contagem de Células Somáticas, em aparelho eletrônico Somacount 300. Foram efetuadas correlações entre Contagem de Células Somáticas, CMT, produção de leite, proteína, gordura e sólidos totais, que foram analisadas pelo SAEG (1997). A média de células somáticas foi de 63.380 células/mL, a produção diária de leite, de 4,07 $\pm 1,3 \mathrm{~kg}$ e a produção ajustada para os 270 dias, de 1214,25 $\pm 293,54 \mathrm{~kg}$. Não foram encontradas correlações entre produção de leite, contagem de células somáticas e CMT. Para CCS e CMT, a correlação foi positiva e significativa $(r=0,53)$.

Palavras-chave: Murrah, contagem de células somáticas, California Mastitis Test, produção de leite

\section{Correlation Between the California Mastitis Test (CMT) and Somatic Cells Count on Milk from Murrah Buffalo Cows}

\begin{abstract}
The objective of this trial was to investigate correlations among the California Mastitis Test, somatic cells count (SCC), and milk yield. Milk samples were collected from thirty-eight Murrah buffalo cows in the years of 2002 and 2003 . Milking management included cleaning teats with individual paper towel followed by attachment of the milk units in cows that were milked once daily. The CMT was done immediately after teat cleaning and collected milk samples were sent to the laboratory for determination of SCC using a Somacount 300. Correlations including variables such as SCC, CMT, milk yield, and percentages of fat, protein, and total solids were done using SAEG (1997). Somatic cells count averaged 63.380 cells/mL while average milk production and milk production adjusted for 270 days were $4.07 \pm 1.3 \mathrm{~kg}$ and $1214.25 \pm 293.54 \mathrm{~kg}$, respectively. No significant correlations between milk yield and SCC and milk yield and CMT were observed in this study. However, a positive and significant correlation (0.53) between SCC and CMT was found.
\end{abstract}

Key Words: Murrah, somatic count cells, California Mastitis Test, milk yield

\section{Introdução}

O leite de búfalas, por apresentar altos teores de proteína, gordura e sólidos totais, vem despertando cada vez mais o interesse de pequenas e médias agroindústrias do ramo, dispostas a investir na fabricação de produtos diferenciados (Faria, 1997). O leite bubalino é na sua totalidade destinado à produção de mozzarela e derivados, destacando-se pela alta quantidade de gordura, proteína e sólidos totais (Andrighetto, 2004). Portanto, deve-se conferir especial atenção à mastite bubalina, que pode depreciar o valor nutritivo do leite e diminuir o rendimento na produção dos derivados do leite.
Mastite é a inflamação da glândula mamária e pode ser causada por muitos microrganismos (Langoni, 1999), podendo se manifestar na forma clínica ou subclínica (Costa \& Watanabe, 1999). O termo células somáticas do leite é utilizado para designar todas as células presentes no mesmo, incluindo as de origem sangüínea (leucócitos) e as de descamação do epitélio glandular secretor. No entanto, em uma glândula mamária infectada, as células de defesa correspondem de 98 a 99\% das células encontradas noleite (Philpot \& Nickerson, 1991). Desse modo, a contagem de células somáticas (CCS) do leite indica, de maneira quantitativa, o grau de infecção da glândula mamária (Machado et al., 2000).

\footnotetext{
1 Prof.Dr. do DPEA/FMVZ/Unesp-Botucatu. Pesquisador do CNPq (andrejorge@fmvz.unesp.br).

2 Doutoranda em Zootecnia da FMVZ/Unesp-Botucatu. Bolsista CAPES (andrighetto@fca.unesp.br).

${ }^{3}$ Graduanda em Zootecnia. FMVZ/Unesp-Botucatu. Bolsista PIBIC-Reitoria Unesp.

4 Doutoranda em Ciências Biológicas pelo IBB/UNESP-Botucatu-SP

${ }^{5}$ Mestrando em Medicina Veterinária, FMVZ/Unesp-Botucatu.

${ }^{6}$ Prof. Dr. do DHVSP da FMVZ/Unesp-Botucatu (domingues@fmvz.unesp.br).
} 
Níveis elevados de células somáticas podem provocar queda no valor nutritivo (Costa et al., 1998) e na produção de leite, aumento da quantidade de leite descartado pelo uso de antibióticos em vacas tratadas, elevação do custo com medicamentos e dos gastos com assistência técnica (Petim-Batista, 1996) e, conseqüentemente, diminuição da vida produtiva dos animais (Domingues et al., 1999).

É possível a redução do número de células somáticas no leite, desde que não sejam pretendidas soluções a curto prazo e que, com a inclusão da Contagem de Células Somáticas nos programas de seleção, seja considerado o equilíbrio econômico, entre um pequeno progresso na produção de leite até a menor incidência de mastite e, conseqüentemente, melhor qualidade do leite, como exigido pelas indústrias de laticínios no pagamento diferenciado por qualidade do leite (Fonseca \& Santos, 2000).

Vários métodos têm sido recomendados para diagnosticar a incidência de mastite subclínica nos rebanhos leiteiros. Entre eles, pode-se citar o California Mastitis Test (CMT), Wisconsin Mastitis Test (WMT) e a Contagem de Células Somáticas (CCS) (Cardozo, 1996).

OCMT é utilizado mundialmente no diagnóstico da mastite subclínica e tem como vantagem poder ser empregado no local do rebanho, no momento em que os animais são ordenhados (Brito et al., 1997), além de ser prático, ter baixo custo e fornecer resultados imediatos (Enevoldsen et al., 1995). Em virtude de sua fácil execução e interpretação, o CMT tem sido foco de muitos estudos, nos quais o principal objetivo é determinar o escore que melhor reflita a quantidade de células somáticas existentes no leite (Winter et al., 1999).

Schuppell \& Schwope (1998) encontraram correlação significativa entre o CMT e a CCS. Gallina et al. (1996) relataram correlação positiva e significativa de 0,76 entre a CCS e o CMT, e correlação negativa e significativa entre CCS e produção de leite $(r=-0,250$.

Vianni et al. (1999) afirmaram que o CMT mostrou elevada eficiência na estimativa do número de células somáticas do leite bubalino. Esses autores demonstraram elevada concordância $(93,7 \%)$ entre os resultados obtidos no CMT e as contagens de células somáticas em amostras de leite de búfalas.

Considerando-se a escassez de informações sobre a mastite bubalina, realizou-se este trabalho com o objetivo de avaliar a eficiência do CMT na estimativa do número de células somáticas presentes no leite bubalino e a influência do número de células somáticas sobre a produção e composição do leite.

\section{Material e Métodos}

O experimento foi realizado na Área de Produção de Bubalinos do Departamento de Produção e Exploração Animal, da Faculdade de Medicina Veterinária e Zootecnia (FMVZ), Unesp, em Botucatu/SP, cujas coordenadas geográficas são latitude sul $22^{\circ} 51^{\prime} \mathrm{e}$ longitude oeste $48^{\circ} 26^{\prime}$, altitude média $800 \mathrm{~m}$ no nível do mar, temperatura média anual $20,2^{\circ} \mathrm{C}$ e precipitação média anual de $1.464 \mathrm{~mm}$.

Foram utilizados dados de 38 búfalas em lactação, em um total de 544 amostras nos anos de 2002 e 2003. Os animais foram mantidos em pastagem de Brachiaria decumbens e, durante o inverno, foram suplementados com silagem de sorgo e concentrado (49\% de milho desintegrado, $28 \%$ de farelo de algodão, $11 \%$ de farelo de trigo e $2,75 \%$ de mistura mineral na matéria seca).

A ordenha era realizada uma vez ao dia em ordenhadeira mecânica tipo balde ao pé. Os animais eram submetidos à higienização dos tetos, antes e após a ordenha, com solução iodada. O controle leiteiro foi realizado mensalmente e as amostras de leite foram colhidas, para análise dos teores de gordura, proteína e sólidos totais. As análises foram efetuadas de acordo com as Normas Analíticas do Instituto Adolfo Lutz (1976) e com os procedimentos descritos no "Standard Methods for Examination of Dairy Products" (1975), no Departamento de Gestão e Tecnologia Agroindustrial, da Faculdade de Ciências Agronômicas (FCA), da Unesp-Campus de Botucatu. Foram calculadas a produção média diária de leite e a de leite corrigida para os 270 dias, utilizando-se os fatores de correção apresentados por Cerón-Muñoz et al. (2002).

O CMT foi realizado imediatamente após higienização dos tetos, sendo o reagente do CMT preparado com detergente comercial, de acordo com a metodologia de Langenegger et al. (1970). Depois de realizado o CMT, as amostras de leite foram coletadas em frasco com dicromato de potássio $(1 \%)$ e enviadas ao laboratório do Departamento de Higiene Veterinária e Saúde Pública (HVSP) da FMVZ/Unesp-Botucatu, para realização da Contagem de Células Somáticas, em aparelho eletrônico Somacount 300.

A interpretação do CMT foi realizada da seguinte maneira: o escore 1 (sem presença de reação entre o reagente e o leite) indica uma reação completamente negativa; 2: reação suspeita (traços); 3: reação fracamente positiva $(+)$; 4 : reação positiva $(++)$ e; 5 : 
reação fortemente positiva $(+++)$ (Philpot \& Nickerson, 1991).

Foram efetuadas correlações entre Contagem de Células Somáticas, California Mastitis Test, produção de leite, porcentagem de proteína, gordura e sólidos totais. A CCS foi transformada em escore linear, utilizando-se a função EL $=\left[\log _{2}(\mathrm{CCS} / 100.000)\right]$ +3 proposta por Dabdoub \& Shook (1984).

A correlação dos dados de CCS e CMT com os demais parâmetros (proteína, gordura e sólidos totais) foi analisada pelo método não-paramétrico de Spermam, uma vez que CCS e CMT não apresentam distribuição normal dos dados. Para as correlações entre produção de leite, proteína, gordura e sólidos totais, no entanto, foi utilizado o método paramétrico de Pearson. Para a realização das análises, foi utilizado o Sistema para Análises Estatísticas e Genéticas - SAEG (UFV, 1997).

\section{Resultados e Discussão}

Constam na Tabela 1 os resultados das produções de leite, do período de lactação, da composição do leite e a porcentagem média de células somáticas do leite do rebanho nos anos de 2002 e 2003.

Os dados encontrados para produção de leite corrigida para os 270 dias estão de acordo com os encontrados por Tonhati et al. (2000), que observaram valores médios de $1.259,47 \mathrm{~kg}$ em búfalas Murrah e seus mestiços pertencentes a rebanhos bubalinos do estado de São Paulo, e por Andrighetto (2004), que observou produção de $1.228,06 \mathrm{~kg}$ e $4,23 \mathrm{~kg} / \mathrm{dia}$ quando avaliou a produção de leite de búfalas Murrah.

As porcentagens de proteína e gordura foram próximas às encontradas por Andrighetto et al. (2003), Jorge et al. (2002) e Almeida (2000), enquanto a porcentagem de sólidos totais foi inferior, variando de 14,37 a $18,99 \%$.

O leite bubalino apresentou baixo número de células somáticas (CCS) em relação ao de rebanhos bovinos com alto padrão de qualidade. No estado de Wisconsin, Estados Unidos, o leite bovino de rebanhos com alto padrão de qualidade apresenta CCS que varia de 130.000 a 200.000 células/mL (Ruegg, 2001) e, no Canadá, a média mensal tem variado de 225.000 a 260.000 células/mL (Godkin, 2000).

As búfalas são consideradas menos susceptíveis à mastite que as vacas, por apresentarem o Ductus papilaris mais musculoso, com maior quantidade de fibras e vasos sanguíneos, funcionando como uma barreira mais eficiente contra as infecções (Lau, 1994).

Outro fator importante é a lactoferrina, uma substância antibacteriana presente no leite que compete com as bactérias pelo ferro, tornando-o indisponível e impedindo seu crescimento bacteriano. O leite bubalino apresenta maior concentração de lactoferrina que o leite bovino (Bathia \& Valsa, 1994), o que favorece a menor incidência de mastite nessa espécie.

Ainda não há um padrão de qualidade para o leite bubalino. Dados da literatura mostram baixas contagens no leite bubalino quando comparado ao leite bovino. Cerón-Muñoz et al. (2002), ao avaliarem a CCS de 1.630 búfalas, observaram média de 79.000 células/mL, enquanto neste estudo obteve-se média para a CCS de 63.380 células $/ \mathrm{mL}$.

Rebanhos com baixas CCS têm menor risco de contaminação do leite com resíduos de antibióticos e, por conseqüência do melhor manejo, apresentam menor quantidade bactérias no leite cru. Altas porcentagens de células somáticas reduzem o rendimento dos queijos e derivados pela redução dos teores de proteína,

Tabela 1 - Médias e desvios-padrão da produção média diária de leite e de leite corrigida para 270 dias, do período de lactação, das porcentagens de gordura, proteína, sólidos totais e de células somáticas no leite de búfalas Murrah nos anos 2002 e 2003

Table 1 - Means and standard errors for adjusted milk yield (270 days), daily milk yield, days in milk, percentages of fat, protein, and total solids and somatic cells count of Murrah buffalo cows in the years of 2002 and 2003

\begin{tabular}{|c|c|}
\hline $\begin{array}{l}\text { Parâmetro } \\
\text { Parameter }\end{array}$ & $\begin{array}{l}\text { Média } \\
\text { Mean }\end{array}$ \\
\hline $\begin{array}{l}\text { Produção diária de leite }(\mathrm{kg}) \\
\text { Daily milk yield }(\mathrm{kg})\end{array}$ & $4,07 \pm 1,3$ \\
\hline $\begin{array}{l}\text { Produção de leite corrigida } \\
\text { para } 270 \text { dias }(\mathrm{kg}) \\
\text { Milk yield corrected } \\
\text { for } 270 \text { days }(\mathrm{kg})\end{array}$ & $1214,25 \pm 293,54$ \\
\hline $\begin{array}{l}\text { Período de lactação (dias) } \\
\text { Days in milk (days) }\end{array}$ & $226,14 \pm 28,53$ \\
\hline $\begin{array}{l}\text { Gordura }(\%) \\
\text { Fat }(\%)\end{array}$ & $5,10 \pm 1,71$ \\
\hline $\begin{array}{l}\text { Proteína }(\%) \\
\text { Protein }(\%)\end{array}$ & $3,92 \pm 0,82$ \\
\hline $\begin{array}{l}\text { Sólidos totais }(\%) \\
\text { Total solids }(\%)\end{array}$ & $13,88 \pm 2,14$ \\
\hline $\begin{array}{l}\text { Contagem de células } \\
\text { somáticas (x } 1000 \text { células } / \mathrm{mL}) \\
\text { Somatic cells count (x } 1000 \text { cells } / \mathrm{mL})\end{array}$ & $63,38 \pm 399,19$ \\
\hline
\end{tabular}


gordura e sólidos totais, além de provocar a rancidez e alterar o aroma e a textura (Godkin, 2000).

O leite de búfalas apresentou excelente qualidade quanto à porcentagem de células somáticas, o que favorece a produção de queijos e derivados. Essa informação é muito importante para a bubalinocultura leiteira já que o leite bubalino é destinado na sua totalidade para a produção de leite e derivados (Andrighetto, 2004).

O número de amostras e a proporção de ocorrência do CMT estão apresentados na Tabela 2. Observa-se que a porcentagem de amostras negativas (escore 1$)$ foi elevada $(82,35 \%)$ e que a de amostras com escores 3, 4, 5 foi baixa.

A relação entre os escores e o valor médio obtido para a reação negativa (escore 1 ) foi de 12,83 (x1.000 células $/ \mathrm{mL}$ ). Para os escores 2, 3, 4 e 5, os valores foram de 46,81, 177,32, 641,85, 2.949,44 (x1.000 células $/ \mathrm{mL}$ ), respectivamente. Os valores médios de CCS obtidos para os escores de CMT foram abaixo das médias obtidas pelo National Mastists Council (1990) para valores médios de rebanhos bovinos. Brito et al. (1997), ao observarem relação entre CMT e CCS de bovinos, também encontraram valores médios de CCS e CMT superiores aos encontrados neste estudo.

Para as diferentes reações do CMT, Silva et al. (2001) obtiveram as médias celulares de 45, 108 e 112 (x1000 células/mL) para os escores 1,2 e 3, respectivamente e médias de 444 e 1189 (x 1000 células/mL) para os escores 4 e 5 , respectivamente.
O escore de células somáticas facilita a interpretação dos resultados, representando a distribuição das observações (Figura 1).

Das 544 observações realizadas, $417(76,7 \%)$ corresponderam ao escore zero, que apresenta contagens ente 1 e 17 (x 1000 células/mL). Em experimento avaliando a contagem de células somáticas em rebanhos bubalinos, Cerón-Muñoz et al. (2002) obtiveram menor porcentagem de observações no escore zero $(37,8 \%)$ que a verificada neste estudo.

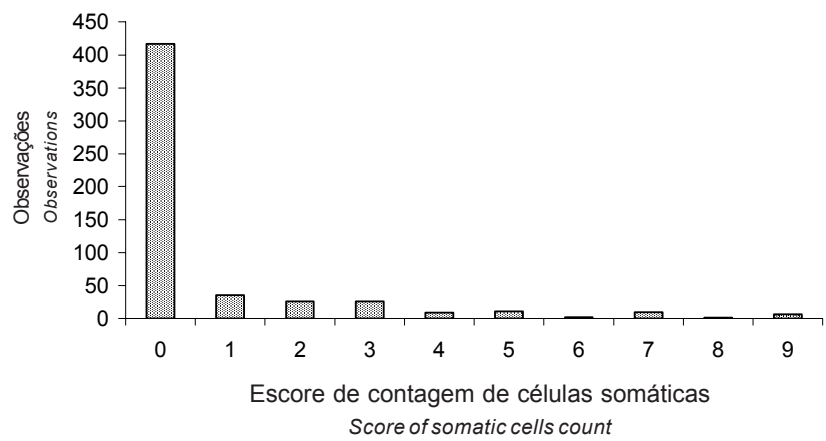

Figura 1 - Distribuição da porcentagem de células somáticas nos diferentes escores lineares, em que: escore $0=0-17$ células $/ \mathrm{mL} ; 1=18$ 34 células $/ \mathrm{mL} ; 2$ = 35-70 células $/ \mathrm{mL} ; 3=71$ 140 células $/ \mathrm{mL} ; 4=141-282$ células $/ \mathrm{mL} ; 5=$ 283-565 células $/ \mathrm{mL} ; 6=566-1130$ células $/$ $\mathrm{mL}) ; 7=1131-2262$ células $/ \mathrm{mL} ; 8=2263$ 4525 células $/ \mathrm{mL}$; e $9=>4525$ células $/ \mathrm{mL}$.

Figure 1 - Distribuition of somatic cells count on different scores, where, score 0 (0-17 cells $/ \mathrm{mL}), 1$ (18 - 34 cells $/ \mathrm{mL}), 2$ (35-70 cells $/ \mathrm{mL}), 3$ (71-140 cells $/ \mathrm{mL})$, 4 (141-282 cells $/ \mathrm{mL}), 5$ (283-565 cells/mL), 6 (566$1130 \mathrm{cells} / \mathrm{mL}), 7$ (1131-2262 cells $/ \mathrm{mL}), 8$ (2263$4525 \mathrm{cells} / \mathrm{mL})$ e 9 (>4525 cells $/ \mathrm{mL})$.

Tabela 2 - Contagem de Células Somáticas (CCS) do leite de búfalas Murrah dos anos de 2002 e 2003 distribuídas entre diferentes classes de escores do California Mastitis Test (CMT)

Table 2 - Somatic cells count (SCC) of milk from Murrah buffalo cows in the years of 2002 and 2003 on different California Mastitis Tests (CMT) scores

\begin{tabular}{|c|c|c|c|c|c|}
\hline \multirow[t]{2}{*}{$\begin{array}{l}\text { Escore do CMT } \\
\text { CMT score }\end{array}$} & \multirow[t]{2}{*}{$\begin{array}{l}\mathrm{N}^{\mathrm{o}} \text { de amostras } \\
N \text {. of samples }\end{array}$} & \multicolumn{4}{|c|}{$\begin{array}{l}\text { CCS }(\times 1000 \text { células } / \mathrm{mL}) \\
\text { SSC }(x 1000 \text { cells } / \mathrm{mL})\end{array}$} \\
\hline & & $\begin{array}{l}\text { Mínimo } \\
\text { Minimum }\end{array}$ & $\begin{array}{l}\text { Máximo } \\
\text { Maximum }\end{array}$ & $\begin{array}{l}\text { Média } \\
\text { Mean }\end{array}$ & $\begin{array}{l}\text { Percentual } \\
\text { Percentage }\end{array}$ \\
\hline 1 & 448 & 0 & 564 & 12,83 & 82,35 \\
\hline 2 & 60 & 0 & 350 & 46,81 & 11,03 \\
\hline 3 & 15 & 0 & 795 & 177,32 & 2,76 \\
\hline 4 & 11 & 63 & 1563 & 641,85 & 2,02 \\
\hline 5 & 10 & 1218 & 6980 & 2949,44 & 1,84 \\
\hline Total & 544 & & & & 100 \\
\hline
\end{tabular}


Ainda na Figura 1, observa-se que, à medida que o escore de células somáticas aumentou, o número de observações foi reduzido. Ruegg (2001) observou, em bovinos leiteiros, que até o escore 2 , não há redução da produção de leite dos animais.

$\mathrm{Na}$ Tabela 3 encontram-se as correlações entre os parâmetros analisados. Não foram encontradas correlações entre a proporção de células somáticas e a produção de leite e porcentagens de proteína e gordura e entre o CMT e a produção de leite e porcentagens de proteína, de gordura e sólidos totais.

Por outro lado, foram encontradas correlações significativas entre a CCS e o CMT $(r=0,53)$, entre a porcentagem de gordura e a de sólidos totais $(\mathrm{r}=$ $0,60)$ e entre CCS e porcentagem de sólidos totais $(\mathrm{r}=-0,15)$.

Silva et al. (2001) também encontraram correlações significativas $(r=0,63)$ entre CCS e CMT e entre CMT e produção de leite $(r=-0,27)$. Resultados semelhantes foram obtidos por Gallina et al. (1996), que relataram correlação significativa $(\mathrm{r}=-0,25)$ entre o CMT e a produção de leite. Por outro lado, Pereira et al. (1999), avaliando 80 vacas bovinas, não encontraram correlações significativas entre CCS e CMT.

Os valores de CCS encontrados no rebanho estudado foram baixos: $18,87 \%$ das amostras apresentaram zero células $/ \mathrm{mL}$; $63,29 \%$, abaixo de 50.000 células $/ \mathrm{mL}$; $13,72 \%$, de 50.001 a 100.000 células/mL; e $4,12 \%$, mais que 100.000 células/mL. Essa distribuição justifica a baixa e não-significativa correlação entre o número de células somáticas e a produção de leite, pois não houve altas porcentagens de células somáticas que pudessem estar diminuindo a produção de leite e alterando sua composição (porcentagem de proteína e gordura).

Ruegg (2001), em uma revisão de 19 estudos com rebanhos bovinos relacionando CCS e produção de leite, concluiu que a quantidade de células somáticas acima de 50.000 células $/ \mathrm{mL}$ resultam em perdas na produção de leite e que a duplicação desses valores após 50.000 células/mL ocasiona uma perda de 0,4 a $0,6 \mathrm{~kg}$ de leite por dia, o que confirma, no presente estudo, que o baixo número de células somáticas pode não ter apresentado correlação com a produção, uma vez que $77,01 \%$ das amostras apresentaram valores abaixo de 50.000 células $/ \mathrm{mL}$.

O CMT também apresentou $82,35 \%$ das amostras negativas (Tabela 2), o que também justifica a-não correlação entre os resultados do CMT e a produção de leite, visto que não houve altos escores que pudessem estar diminuindo a produção de leite, pois altos escores estão relacionados à redução da produção de leite (Ruegg, 2001; Fonseca \& Santos, 2000).

Tabela 3 - Correlações entre Contagem de Células Somáticas (CCS), Califórnia Mastitis Test $(\mathrm{CMT})$, a produção média diária de leite $(\mathrm{kg})$ e as porcentagens de gordura, de proteína e de sólidos totais de búfalas Murrah nos anos 2002 e 2003

Table 3 - Correlations among Somatic Cells Count (SCC), California Mastitis Test (CMT), daily milk production $(\mathrm{kg})$, percentages of fat, protein, and total solids from Murrah buffalo cows in years 2002 and 2003

\begin{tabular}{|c|c|c|c|c|c|c|}
\hline $\begin{array}{l}\text { Parâmetro } \\
\text { Parameter }\end{array}$ & $\begin{array}{l}\text { CMT } \\
C M T\end{array}$ & $\begin{array}{l}\text { CCS } \\
S C C\end{array}$ & $\begin{array}{l}\text { Leite } \\
\text { Milk }\end{array}$ & $\begin{array}{l}\text { Proteína } \\
\text { Protein }\end{array}$ & $\begin{array}{l}\text { Gordura } \\
\text { Fat }\end{array}$ & $\begin{array}{l}\text { Sólidos totais } \\
\text { Total solids }\end{array}$ \\
\hline $\begin{array}{l}\mathrm{CMT} \\
C M T\end{array}$ & - & - & - & - & - & - \\
\hline $\begin{array}{l}\mathrm{CCS} \\
S C C\end{array}$ & $0,53 * *$ & - & - & - & - & - \\
\hline $\begin{array}{l}\text { Leite } \\
\text { Milk }\end{array}$ & $-0,04$ & $-0,04$ & - & - & - & - \\
\hline $\begin{array}{l}\text { Proteína } \\
\text { Protein }\end{array}$ & 0,11 & 0,18 & $-0,06$ & - & - & - \\
\hline $\begin{array}{l}\text { Gordura } \\
\text { Fat }\end{array}$ & 0,03 & $-0,07$ & $-0,05$ & $-0,10$ & - & - \\
\hline $\begin{array}{l}\text { Sólidos totais } \\
\text { Total solids }\end{array}$ & 0,03 & $-0,15^{*}$ & $-0,10$ & 0,09 & $0,60 * *$ & - \\
\hline
\end{tabular}

${ }^{*} \mathrm{P}<0,05 ;{ }^{* *} \mathrm{P}<0,01\left({ }^{*} \mathrm{P}<0.05 ;{ }^{* *} P<0.01\right)$. 


\section{Conclusões}

Búfalas Murrah submetidas a boas condições de manejo de ordenha apresentaram leite com baixas porcentagens de células somáticas, mostrando ser uma excelente matéria-prima para a fabricação de queijos e derivados, uma vez que altos valores de células somáticas alteram a composição do leite, comprometendo a qualidade de seus derivados.

A contagem de células somáticas e o CMT não apresentaram correlação com a composição e produção do leite.

O CMT apresentou correlação positiva e significava com a contagem de células somáticas, comprovando ser um teste eficaz para a detecção de mastite subclínica em rebanhos bubalinos.

\section{Literatura Citada}

ALMEIDA, V.M.; BARRETO JR., R.A; COSTA, F.N. Características físico-químicas do leite de búfalas de algumas granjas leiteiras do Maranhão. Revista do Instituto de Laticínios Cândido Tostes, v.54, n.5, p.3-5, 2000.

ANDRIGHETTO, C. Efeito da monensina sódica na produção, composição do leite e escore de condição corporal de búfalas Murrah no início da lactação. Botucatu: Universidade Estadual Paulista, 2004. 37p. Dissertação (Mestrado em Zootecnia) - Universidade Estadual Paulista, 2004.

ANDRIGHETTO, C.; JORGE, A.M.; PICCININ, A. et al. Produção de mozzarella e composição do leite de búfalas alimentadas com ionóforos. In: REUNIÃO CIENTÍFICA DE CIÊNCIAS AGRÁRIAS DO LAGEADO, 10., 2003, Botucatu. Anais... Botucatu: Faculdade de Ciências Agronômicas, 2003. CD-ROM

BATHIA, K.L.; VALSA, C. Lactoferrin level in buffalo milk. In: BUFFALO WORLD CONGRESS, 1994, São Paulo, 4., Proceedings... São Paulo: Associação Brasileira dos Criadores de Búfalos, 1994. v.2. p.162.

BRITO, J.R.F.; CALDEIRA, G.A.V.; VERNEQUE, R.S. et al. Sensibilidade e especificidade do "California Mastitis Test" como recurso diagnóstico da mastite subclínica em relação à contagem de células somáticas. Pesquisa Veterinária Brasileira, v.17, n.2, p.49-53, 1997.

CARDOZO, R.M. Avaliação de testes para diagnóstico de mastites subclínicas em bovino de leite. Revista Unimar, v.18, n.3, p.627-636, 1996.

CERÓN-MUÑOZ, M.; TONHATI, H.; DUARTE, J. et al. Factors affecting somatic cell counts and their relations with milk and milk constituent yield in buffaloes. Journal of Dairy Science, v.85, p.2885-2889, 2002.

COSTA, E.O.; WATANABE, E.T. Tratamento de mastite In: ENCONTRO DE PESQUISADORES EM MASTITE, 3., 1999. Botucatu. Anais... Botucatu: Faculdade de Medicina Veterinária e Zootecnia, 1999. p.87-101.

COSTA, E.O.; RIBEIRO, A.R.; GARINO JR., F. et al. Avaliação da condutibilidade elétrica do leite de glândula mamária com mastite: correlação com CMT e exames microbiológicos. Napgama, v.1, n.1, p.3-8, 1998.
DABDOUB, S.A.M.; SHOOK, G.E. Phenotypic relations amoung milk yield, somatic count cels, and mastitis. Journal of Dairy Science, v.67, p.163-164, suplemento 1, 1994.

DOMINGUES, P.F; LANGONI, H.; ROCHA, N.S. et. al. Concentração plasmática de cobre, ferro, zinco, vitamina C e Beta caroteno em vacas com mastite subclínica. In: ENCONTRO DE PESQUISADORES EM MASTITE, 3., 1999, Botucatu. Anais... Botucatu: Faculdade de Medicina Veterinária e Zootecnia, 1999. p.143.

ENEVOLDSEN, C; GROHN, Y.; THISEN, I. Dairy cow characteristics related to Staphylococcus aureus isolation from quarter samples. Journal of Dairy Research, v.62, n.1, p.69-81, 1995.

FARIA, M.H. Produção de leite e seus constituintes em diferentes grupos genéticos nos bubalinos (Bubalus bubalis). Jaboticabal: Universidade Estadual Paulista, 1997, 75p. Dissertação (Mestrado em Zootecnia) - Universidade Estadual Paulista, 1997.

FONSECA, L.F.L.; SANTOS, M.V. Qualidade do leite e controle de mastite. São Paulo: Editorial Lemos, 2000. 175p.

GALLINA, M.A; MORALES, R; LÓPEZ, B. et al. Sources of variation of somatic cell count during lactation in Mexican dairy goats. In: INTERNACIONAL CONFERENCE ON GOATS, 6., 1996, Beijing. Proceedings... Beijing: IGF, 1996, v.1, p.325-328.

GODKIN, A. Qualidade do leite ao redor do mundo: O papel da CCS. In: SIMPÓSIO INTERNACIONAL SOBRE QUALIDADE DO LEITE, 2., 2000, Curitiba. Anais... Curitiba: Universidade Federal do Paraná, 2000. v.2, p.9-16.

INSTITUTO ADOLFO LUTZ. Normas analíticas do Instituto Adolfo Lutz. Métodos químicos e físicos para a análise de alimentos. São Paulo: 1976. 371p.

JORGE, A.M.; GOMES, M.I.F.V.; HALT, R.C. Efeito da utilização da somatotropina bovina recombinante (BST) sobre a produção de leite em búfalas. Revista Brasileira de Zootecnia, v.31, n.3, p.1230-1234, 2002.

LANGENEGGER, J.; COELHO, N.M; LANGENEGGER, C.H. et al. Estudo da incidência da mastite bovina na bacia leiteira do Rio de Janeiro. Pesquisa Agropecuária Brasileira, v.5, p.437-440, 1970.

LANGONI, H. Complexidade etiológica da mastite bovina. In: ENCONTRO DE PESQUISADORES EM MASTITES, 3., 1999, Botucatu. Anais... Botucatu: Faculdade de Medicina Veterinária e Zootecnia, 1999. p.3-18.

LAU, H.D. Import diseases buffalo. In: BUFFALO WORLD CONGRESS, 4., 1994, São Paulo. Proceddings... São Paulo. Associação Brasileira dos Criadores de Búfalos, 1994. v.2. p.168.

MACHADO, P.F.; PEREIRA, A.R.; SARRÍES, G.A. Composição do leite de tanques de rebanhos brasileiros distribuídos segundo sua contagem de células somáticas. Revista Brasileira Zootecnia, v.29, n.6, p.1883-1886, 2000.

NATIONAL MASTITIS COUNCIL. Microbiological procedures for the diagnosis of bovine under infection. 3.ed. Arlington: 1990. 34p.

PEREIRA, A.R.; SAIRRES, G.A.; MACHADO, P.F. et al. Correlações entre a produção de leite, contagem de células somáticas, porcentagens de gordura, proteína, lactose e sólidos totais nas ordena da manhã e tarde. In: ENCONTRO DE PESQUISADORES EM MASTITES, 3., 1999, Botucatu. Anais... Botucatu: Faculdade de Medicina Veterinária e Zootecnia, 1999. p.146. 
PETIM-BATISTA, M.F.S. Células somáticas em fêmeas bovinas leiteiras portuguesas - perspectivas da sua alteração quantitativa. Vila Real, PO: UTAD, 1996. 108p. Dissertação (Mestrado em Produção Animal) - UTAD, 1996.

PHILPOT, W.N; NICKERSON, S.C. Mastits: counter attack. Babson Bros Co, 1991. 150p.

RUEGG, P.L. Contagem de células somáticas como ferramenta para avaliação, controle e tratamento de mastite. In: NOVOS ENFOQUES NA PRODUÇÃO E REPRODUÇÃO DE BOVINOS, 5., 2001, Uberlândia. Anais... Uberlândia: CONAPEC Jr, 2001, p.25-33.

UNIVERSIDADE FEDERAL DE VIÇOSA - UFV. SAEG Sistema de Análise Estatística e Genética. Viçosa: 1997.

SCHUPPEL, H.; SCHWOPE, M. Diagnosis of mastitis in goats using the California Mastitis Test and measurement of electric conductivity. Archiv Lebensmittel Hygiene, v.49, n.3, p.61-64, 1998.

SILVA, E.R.; PEREIRA, A.R.; MACHADO, P.M. et al. Associação entre o Califórnia Mastitis Test e a Contagem de Células Somáticas na avaliação da saúde da glândula mamária caprina. Brazilian Journal of Veterinary Research and Animal Science, v.38, n.1, p.46-48, 2001.
STANDARD METHODS FOR THE EXAMINATION OF DAIRY PRODUCTS. Americam Public Healt Association, 13.ed. Washington, D.C.: 1972. 345p.

TONHATI, H.; MUÑOZ, F.C.; OLIVEIRA, J.A. et al. Parâmetros genéticos para a produção de leite, gordura e proteína de bubalinos. Revista Brasileira de Zootecnia, v.29, n.6, p.2051-2056, 2000.

VIANNI, M.C.E.; NADER FILHO, A.; ROSSETTI, D.J.G. et al. Eficiência do California Mastitis Test (CMT) na estimativa do número de células somáticas do leite bubalino. Revista Ciência Veterinária, v.4. p.3-4, 1999.

WINTER, P.; BAUMGARTNER, W. Evaluation of CMT reactions in goat milk. Deutsche Tierarztliche Wochenschrift, v.106, n.1, p.30-34, 1999.

Recebido em: 22/09/04

Aceito em: 31/03/05 